
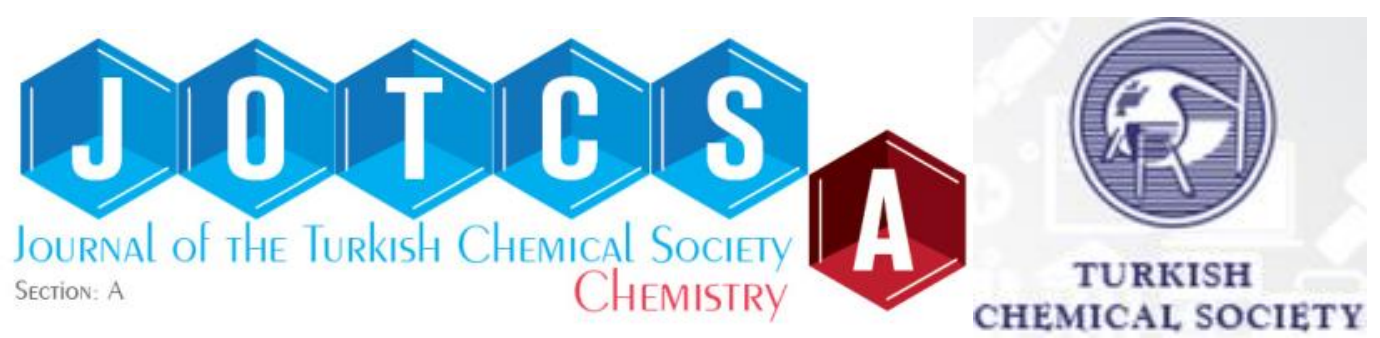

\title{
Molecular Docking Study of Four Chromene Derivatives as Novel HIV-1 Integrase Inhibitors
}

\author{
Nevin Arslan \\ Şırnak University, Faculty of Agriculture, Department of Food Engineering, Şırnak, Turkey
}

Abstract: Four ligands based on Chromene derivatives have been docked into integrase of prototype foamy virus, which has high structural similarity with that of HIV-1 integrase. The Autodock Vina (Vina) software was used for this purpose. The docking scores for the derivatives are $-7.3 \mathrm{kcal} / \mathrm{mol}$, $-7.5 \mathrm{kcal} / \mathrm{mol},-6.9 \mathrm{kcal} / \mathrm{mol}$, and $-7.2 \mathrm{kcal} / \mathrm{mol}$, respectively, which are comparable with that for Raltegravir $(-10.7 \mathrm{kcal} / \mathrm{mol})$. The docking results provide a detailed evidence for the interactions of four Chromene derivatives. The results may lead to the design and development of new drug candidates against AIDS.

Keywords: AIDS, chromene derivatives, molecular docking, HIV-1 integrase inhibitors.

Submitted: November 05, 2018. Accepted: March 01, 2019.

Cite this: Arslan N. Molecular Docking Study of Four Chromene Derivatives as Novel HIV-1 Integrase Inhibitors. JOTCSA. 2019;6(2):133-42.

DOI: https://dx.doi.org/10.18596/jotcsa.478772.

*Corresponding author. E-mail: narslan@sirnak.edu.tr.

\section{INTRODUCTION}

The main reason of the acquired immunodeficiency syndrome (AIDS) is the human immunodeficiency virus type 1 (HIV1 ). This is a progressive, sluggish and degenerative disease of the human immune system. HIV-1 belongs to the retrovirus family, which is classified as a lentivirus (1). The HIV replication cycle involves the integration of viral DNA into the host chromosome, which is an essential process conducted by the viral integrase (IN) protein. This protein, together with reverse transcriptase and protease, is one of three enzymes encoded by HIV (2). The current antiviral therapy for treatment of AIDS includes a combination therapy with reverse transcriptase and protease inhibitors with a potential therapeutic capability (3). The integrase is a $32 \mathrm{kDa}$ enzyme composed of three functional domains (catalytic core domain, an $\mathrm{N}$-terminal domain and a less conserved C-terminal domain) $(4,5)$. It does not have sequence homologue or an equivalent counterpart in the human host cell. Therefore, this makes the protein an attractive drug target (6). There are few integrase inhibitors introduced as promising drug candidates for the treatment of AIDS after the authorization of Raltegravir (7). Despite the effective activity of Raltegravir and several other inhibitors against anti-HIV integrase they possess adverse influences on prolonged usage and develop drug resistance. Thus, there is an urgent requirement to investigate new and potential chemical scaffolds for the treatment of AIDS.

Diketo acids (DKA) possess a metal-chelating function and they can simultaneously coordinate two divalent metal ions. Therefore, they are considered as potent inhibiting proteins which bear divalent metals which are involved in the hydrolysis of endonucleolytic phosphodiesters (8-9). Raltegravir is the first efficient anti-HIV drug targeting HIV-1 IN, which is classified as a diketo acid-based derivative. FDA approved it in October 2007. Besides, Elvitegravir is a monoketo acid 
<smiles>Cc1nnc(C(=O)NC(C)(C)c2nc(C(=O)NCc3ccc(F)cc3)c(O)c(=O)n2C)o1</smiles>

\section{Raltegravir}<smiles>COc1cc(O)c2c(=O)cc(-c3ccccc3)oc2c1OC</smiles>

5-hydroxy-7,8-dimethoxy-2-phenyl-4H-chromen-4-one<smiles>COc1ccc(OC)c(-c2cc(=O)c3c(O)cc(OC)c(OC)c3o2)c1</smiles>

2-(2,5-dimethoxyphenyl)-5-hydroxy7,8-dimethoxy-4H-chromen-4-one<smiles>COc1cc(O)c2c(c1OC)OC(c1ccccc1)CC2=O</smiles>

5-hydroxy-7,8-dimethoxy-2-phenylchroman-4-one<smiles>COc1cccc(-c2cc(=O)c3c(OC)cc(OC)c(OC)c3o2)c1OC</smiles>

2-(2,3-dimethoxyphenyl)-5-hydroxy7,8-dimethoxy-4H-chromen-4-one

Figure 1. Structures of ligands used for molecular docking. (The atoms in interaction with protein or DNA labelled by number in structure file.).

The computational methods have occupied a significant place in drug discovery. These methods are collectively termed pharmacoinformatics. They include virtual screening, structure activity relationship (SAR), pharmacophore and molecular docking. These approaches have widely been employed in the pharmaceutical industry for identification and optimization including several groups who have identified IN inhibitors for HIV therapy (12-17). The current research involves exploring the binding choice of the inhibitory molecules of
HIV IN according to virtual screening and space modelling study together with molecular docking. Chromene derivatives (Figure 1), (L01), (L02), (L03) and (L04) were used as ligands. The structure of the HIV-1 IN has not yet been experimentally determined. Nevertheless, it is known that INs have a high level of conservation especially within their active sites $(6,8,9,17)$ (Calculated catalytic core residues identity between $1 \mathrm{BL} 3 . \mathrm{pdb}$ and 3OYA.pdb with Chimera is 25\%) and the catalytic triad DDE motif which interacts with both target and viral DNA. Recently an X-ray 
structure of prototype foamy virus (PFV) IN has been resolved and thus it can provide a basis for structural explorations of HIV INs $(18,19)$. HIV-1 lacks only Ser217 residue in the immediate vicinity of the catalytic carboxylates of PFV IN. Nevertheless, this residue is not directly involved in the interaction of IN with integrase strand transfer inhibitors (INSTIs) (6).

\section{MATERIAL AND METHOD}

\section{Preparing of Receptor Structure}

We obtained the crystallographic structure of full-length (3OYA.pdb) PFV Integrase from the Protein Data Bank (www.rcsb.org). This structure includes a DNA fragment and Raltegravir. After removing all ligands and water molecules from crystal structure, receptor and ligand files were separately saved by DS Visualizer software. MGL Tools (Version 1.5.7rc1) was used for creating pdbqt files of receptor and ligands needed for docking with Autodock Vina (Vina) (Version 1.1.2).

\section{Preparing of Ligand Structures}

2D structures of ligands were drawn with Chemaxon Marvin Sketch program and also saved as 3D structure file in mol2 file format. Structures were then optimized with semiempirical PM6 method with Gaussian 09 (18) program. Charges were derived by antechamber module of AMBER 14 (19) suite software. Ptbqt files of ligands were prepared with MGL Tools by keeping charges obtained from the antechamber.

\section{Docking Method and Method Validation}

Autodock Vina uses an efficient quasi-Newton and Broyden-Fletcher-Goldfarb-Shanno (BFGS) methods for local optimization (20). Ligands were docked to binding site cavity using $x=-38.7 \AA, y=29.9 \AA$, and $z=-20.2 \AA$ Cartesian coordinates which take catalytic site in. The grid box dimensions used for search space were $28 \AA \times 28 \AA \times 28 \AA$. Docking calculations were performed with exhaustiveness option of 8 (average accuracy) and an energy range of 3 . The Vina gives docking scores as predicted inhibition constants $\left(\mathrm{K}_{\mathrm{i}}\right)$, which is derived from Gibbs free energy of binding calculated by following equations,

$$
\begin{array}{ll}
\Delta G=-R T\left(\ln K_{i}\right) & \text { Eq. } 1 \\
K_{i}=e^{\frac{-\Delta G}{R T}} & \text { Eq. } 2
\end{array}
$$

where R (gas constant) is $1.98 \mathrm{cal} / \mathrm{mol} . \mathrm{K}$, and $\mathrm{T}$ is $298.15 \mathrm{~K}$.

Validation of docking method was performed by re-docking Raltegravir to the crystal structure. Binding mode of Raltegravir to the protein structure is shown in Fig. 2 which shows the ligand is located in a similar mode with its original location.

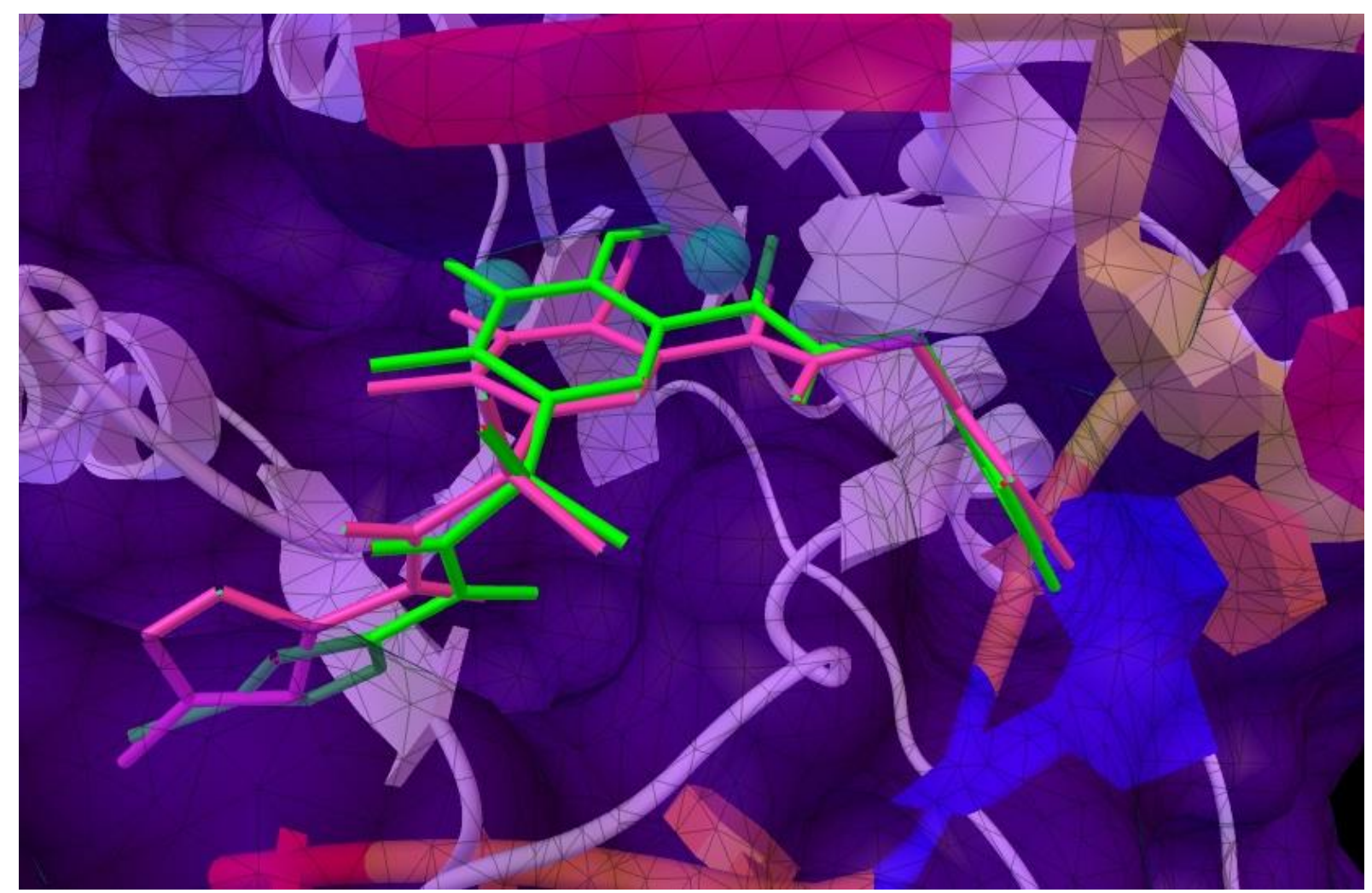

Figure 2. Validation of docking with Autodock Vina (pink: original coordinates, green: docking mode of Raltegravir with Vina) 


\section{RESULTS AND DISCUSSION}

On one hand, the prediction of some properties of molecules is important for their consideration as drug candidates. These are defined by the Lipinski's rules. (21). Analyses demonstrate that all the ligands follow the Lipinski's rule of five and they show moderate water solubility (Table 1 )

Table 1. Molecular properties of ligands according to Lipinski's rules.

\begin{tabular}{|c|c|c|c|c|c|}
\hline Ligands & Molecular Mass & $\begin{array}{l}\text { Hydrogen bond } \\
\text { donor }\end{array}$ & $\begin{array}{l}\text { Hydrogen bond } \\
\text { acceptor }\end{array}$ & $\log P$ & $\begin{array}{c}\text { Molar } \\
\text { Refractivity }\end{array}$ \\
\hline L01 & 298.29 & 1 & 5 & 2.81 & 82.93 \\
\hline L02 & 300.11 & 1 & 5 & 2.61 & 80.51 \\
\hline L03 & 358.34 & 1 & 7 & 2.83 & 95.91 \\
\hline L04 & 358.34 & 1 & 7 & 2.79 & 95.91 \\
\hline
\end{tabular}

Four ligands were successfully docked to PFV IN by Autodock Vina. Raltegravir gave the best docking score which was used for validation of docking method with a score of -10.7 $\mathrm{kcal} / \mathrm{mol}$. L01, L02, L03, and L04 have a docking score of $-7.3 \mathrm{kcal} / \mathrm{mol},-7.5 \mathrm{kcal} / \mathrm{mol}$, $-6.9 \mathrm{kcal} / \mathrm{mol}$, and $-7.2 \mathrm{kcal} / \mathrm{mol}$, respectively. The ligands have quite similar docking scores with comparable magnitude to that of Raltegravir.

X-ray structure of PNV IN (22) demonstrates that Tyr212 (corresponding Tyr 143 in HIV-1
Integrase) is involved in a face-to-face $\Pi-\Pi$ stacked interaction with the oxadiazole ring of Raltegravir. Raltegravir also forms two hydrogen bonds with Tyr212, and two water molecules coordinated with the metal ions. The other important interaction between Raltegravir and receptor (protein and DNA) involves $\Pi-\Pi$ stacking with DC16 (DNA cytosine), DA17 (DNA adenine), GIn215 and Pro214. The electrostatic interaction with both $\mathrm{Mg}$ ions is of course one of the most significant interactions (Figure 3).

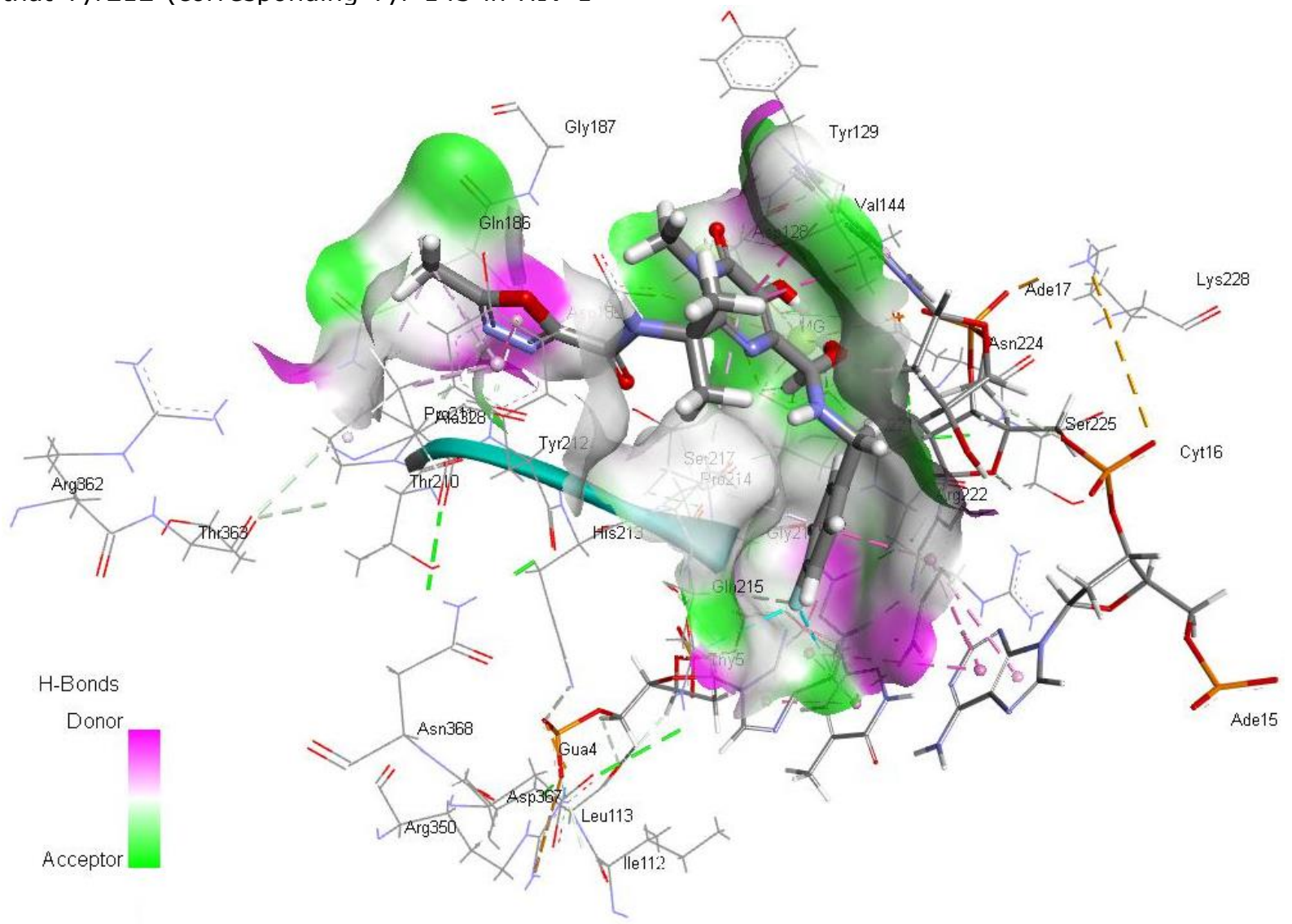

Figure 3. Interaction mode of RAL with IN obtained from docking results. 
All the ligands are placed in catalytic center of integrase and they all interact with both $\mathrm{Mg}$ ions. In L01, $\mathrm{O} 11$ and $\mathrm{O} 20$ atoms form electrostatic interactions with $\mathrm{Mg}$ ions while $\mathrm{O5}$ atom forms a hydrogen bond with $\mathrm{HN}$ atom of DA17. Chromene ring of L01 also forms n- anion, $\pi / \mathrm{CH}$ interaction with Glu221, and Pro214, respectively (Figure 4). L02, which differs from L01 by lacking the double bond between C8 and C9 atoms of chromene, has a similar binding mode compared to that of L01 (Figure 5).

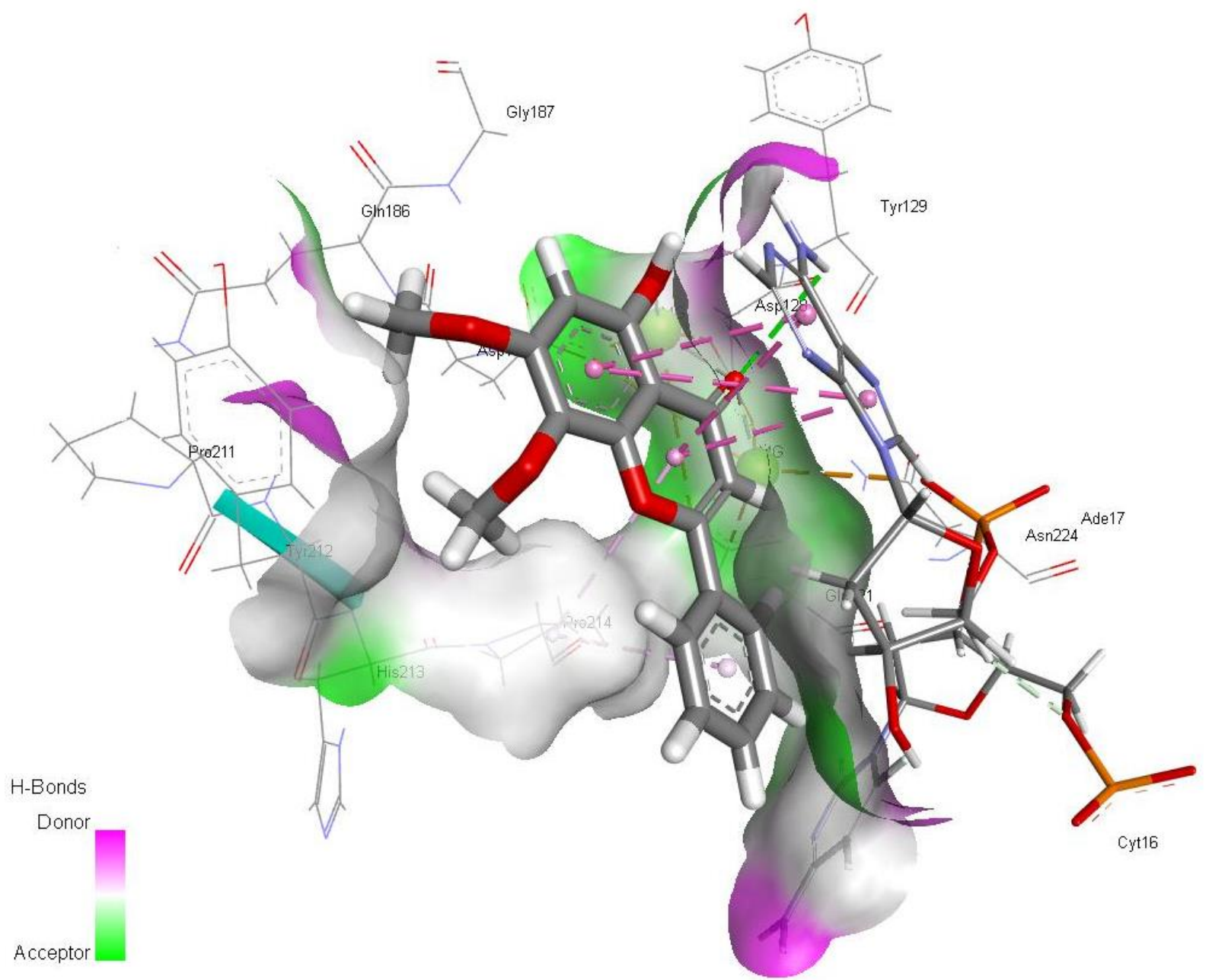

Figure 4. Interaction mode of L01 with IN obtained from docking results. 


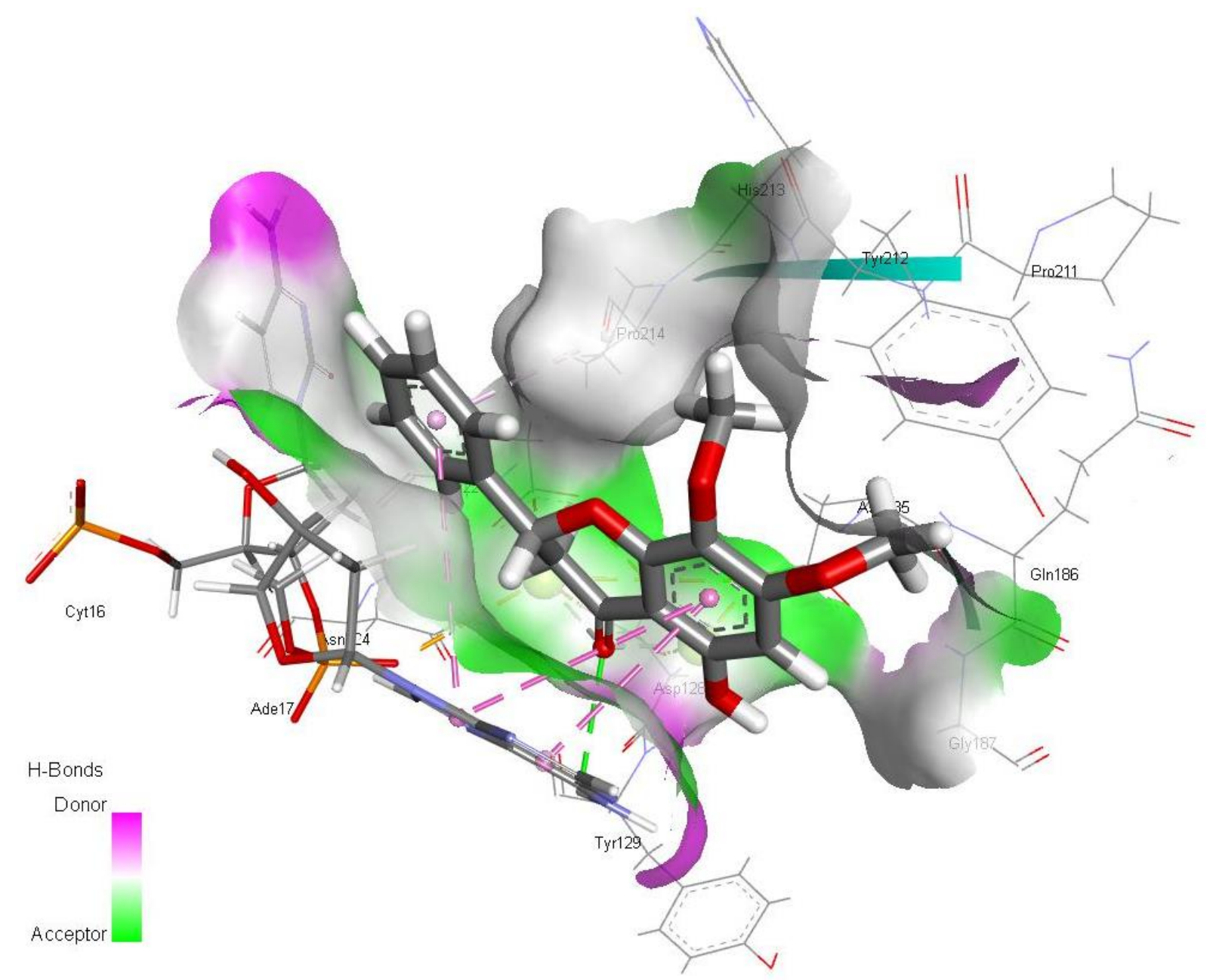

Figure 5. Interaction mode of L02 with IN obtained from docking results.

Unlike other three ligands, L03 forms electrostatic interaction with only $\mathrm{Mg} 397$ atom. The distances between ligand oxygen atoms and $\mathrm{Mg}$ atoms are shown in Table 2. The other interactions of L03 with the receptor include the $\Pi$ - $\Pi$ stacking between chromene and DA17 and $\mathrm{n} / \mathrm{CH}$ interactions between chromene and Pro214 (Figure 6). On the other hand, L04 ligand has two hydrogen bonds, one is between $\mathrm{O} 24$ in the ligand and the amide $\mathrm{NH}$ of Tyr212 and the other is between $\mathrm{H} 6$ in the ligand and OE1 of Glu221 residue. Besides, there are electrostatic interactions of oxygen atoms in the ligand with $\mathrm{Mg}$ atoms and $\pi / \mathrm{CH}$ interaction with Pro214 residue (Figure 7). 


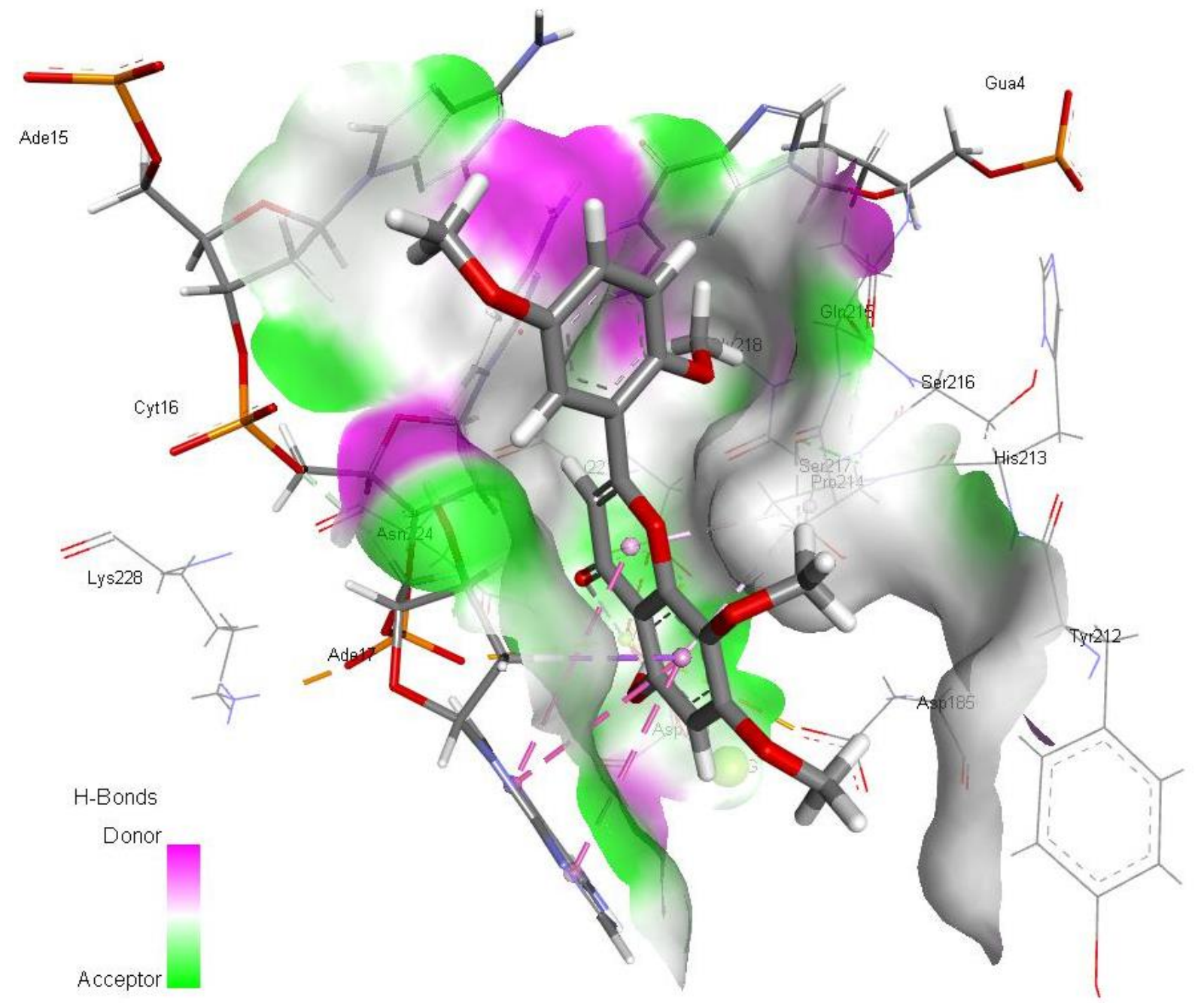

Figure 6. Interaction mode of L03 with IN obtained from docking results. 


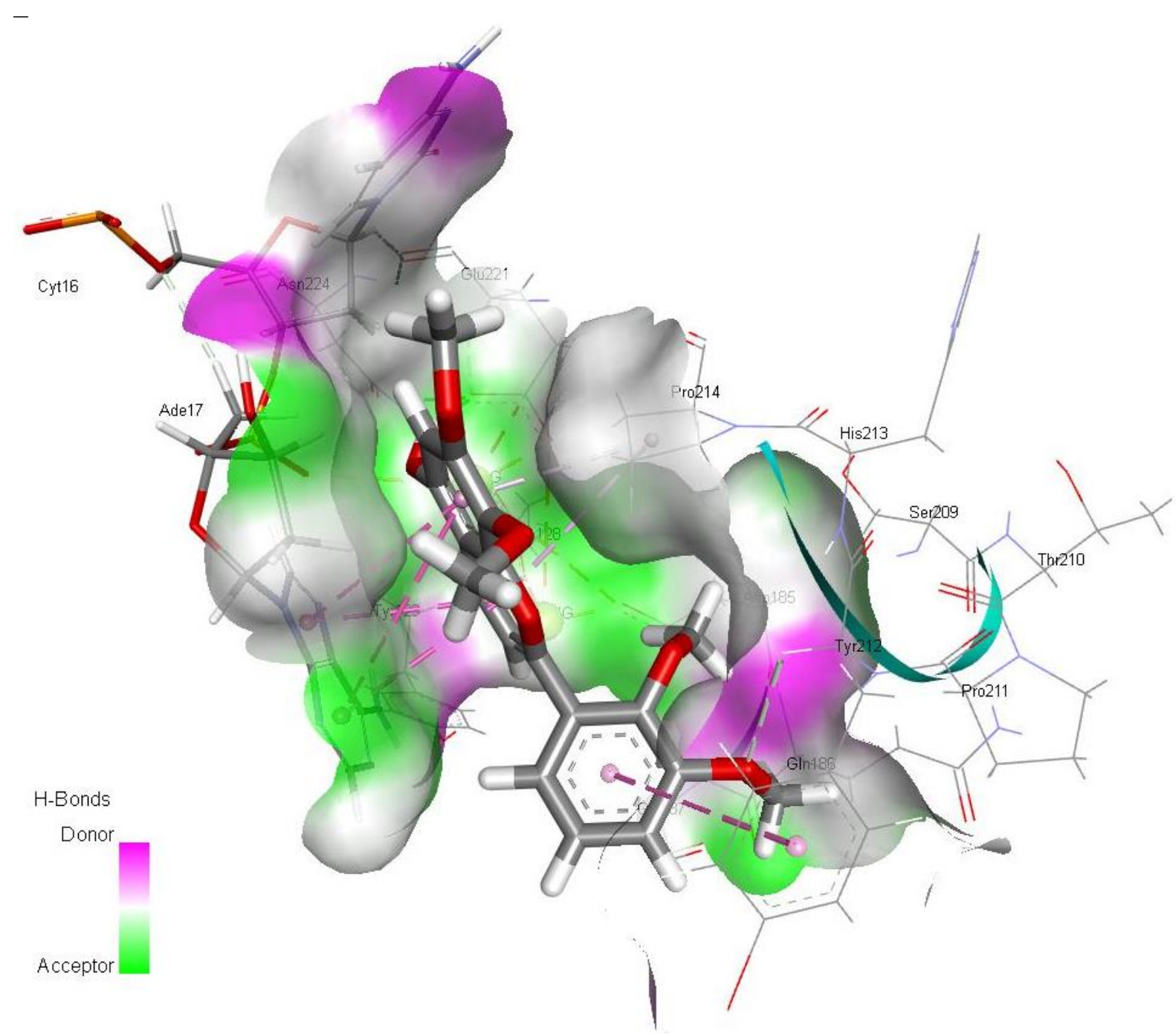

Figure 7. Interaction mode of L04 with IN obtained from docking results.

The binding role and importance of metal ions which are contained in the enzyme is well known (23). Table 2 details the distances between $\mathrm{Mg}^{2+}$ ions and related ligand atoms. Hereunder, except L03-024/Mg396 ligands have an acceptable interaction distance with $\mathrm{Mg}^{2+}$ ions and while all other ligands make an interaction with both $\mathrm{Mg}^{2+}$ ions by one oxygen atom, L03 is in interaction with one $\mathrm{Mg}^{2+}$ ion per oxygen atom (L03-O11/Mg397, L03O24/Mg397). L03-024/Mg396 interaction is weak $(4.03 \AA)$ when comparing with other ligands' equivalent oxygen atoms-Mg interactions.

Table 2. Interaction distances between the oxygen atoms in the ligands with $\mathrm{Mg}$ atoms.

\begin{tabular}{ccc}
\hline Ligand Atoms & MG396 & MG397 \\
\hline L01-O11 & $2.51 \AA$ & $2.60 \AA$ \\
L01-O20 & $2.41 \AA$ & - \\
L02-O11 & $2.43 \AA$ & $2.66 \AA$ \\
L02-O20 & $2.47 \AA$ & - \\
L03-O11 & - & $2.75 \AA$ \\
L03-O24 & $4.03 \AA$ & $2.76 \AA$ \\
L04-O6 & - & $2.27 \AA$ \\
L04-O11 & $2.98 \AA$ & $2.26 \AA$ \\
\hline
\end{tabular}




\section{CONCLUSIONS}

The docking results provide a detailed evidence for the interactions of four Chromene derivatives. Docking scores and interactions of ligands with catalytic core residues and $\mathrm{Mg}$ ions encourage hope for a new ligand group in HIV-1 drug design studies. Also, we note that these ligands need some improvements by adding or removing some fragments. This information may be used for the design and development of new drug candidates against AIDS.

\section{REFERENCES}

1. Borkotoky S. Docking Studies onHIV Integrase Inhibitors Based On Potential Ligand Binding Sites IJBB. 2012;2(3):21-9.

2. Ercan S. Docking and Molecular Dynamics Calculations of Some Previously Studied and Newly Designed Ligands to Catalytic Core Domain of HIV-1 Integrase and an Investigation to Effects of Conformational Changes of Protein on Docking Results. JOTCSA. 2017; 4(1): 243-70.

3. Vandamme A-M, Van Vaerenbergh $\mathrm{K}$, De Clercq E. Anti-human immunodeficiency virus drug combination strategies. Antivir Chem Chemother. $1998 ; 9: 187-203$.

4. Delelis O, Carayon K, Saïb A, Deprez E, Mouscadet J-F. Integrase and integration: biochemical activities of HIV-1 integrase. Retrovirology. 2008; 5:114.

5. Chen Julian C, Krucinski J, Miercke Larry J, Finer-Moore Janet S, Tang Ann $H$, Leavitt Andrew D, Stroud Robert M. Crystal structure of the HIV-1 integrase catalytic core and C-terminal domains: a model for viral DNA binding. Proc Natl Acad Sci USA. 2000;97(15):8233-8.

6. Thomas M, Brady L. HIV integrase: A Target for AIDS therapeutics. Trends Biotechnol. 1997; 15: 167-72.

7. Islama Ataul Md, Pillay Tahir S. Structural requirements for potential HIV-integrase inhibitors identified using pharmacophore-based virtual screening and molecular dynamics studies. Mol. BioSyst. 2016; 12: 98293.

8. Shaw-Reid CA, Munshi V, Graham $P$, Wolfe A, Witmer $M$, Danzeisen $R$, Olsen DB, Carrol SS, Embrey M, Wai JS, Miller MD, Cole JL, Hazuda DJ. Inhibition of HIV-1 ribonuclease $\mathrm{H}$ by a novel diketo acid, 4-[5(benzoylamino)thien-2-yl]-2,4dioxobutanoic acid. J. Biol Chem.2003; 278:2777-80.

9. Grobler Jay A, Stillmock K, Hu B, Witmer M, Felock $P$, Espeseth Amy S, Wolfe A, Egbertson $M$, Bourgeois $M$, Melamed J, Wai John S, Young S, Vacca J, Hazuda Daria J .Diketo acid inhibitor mechanism and HIV-1 integrase: implications for metal binding in the active site of phosphotransferase enzymes. Proc Natl Acad Sci USA. 2002; 99:6661-6.

10. Rowley M.The discovery of Raltegravir, an integrase inhibitor for the treatment of HIV infection. Prog Med Chem. 2008;46:1-28.

11. Summa V, Petrocchi A, Bonelli $F$, Crescenzi B, Donghi M, Ferrara M et al. Discovery of Raltegravir, a potent, selective orally bioavailable HIVintegrase inhititor for the treatment of HIV-AIDS infection. J. Med. Chem.2008;51:5843-55.

12. Kumara Sivakumar $P$, . Patelb Chirag N, Jha Prakash C ,. Pandyab Himanshu A. Molecular dynamics-assisted pharmacophore modeling of caspase3-isatin sulfonamide complex: Recognizing essential intermolecular contacts and features of sulfonamide inhibitor class for caspase-3 binding. Comp Biol Chem. 2017;71:117-28.

13. Sangeetha B, Muthukumaran R, Amutha $\mathrm{R}$ Pharmacophore modelling and electronic feature analysis of hydroxamic acid derivatives, the HIV integrase inhibitors. SAR QSAR Environ Res. 2013; 24:753-771.

14. Bhatt $H$, Patel $P$, Pannecouque $C$. Discovery of HIV-1 Integrase Inhibitors: Pharmacophore Mapping, Virtual Screening, Molecular Docking, Synthesis, and Biological Evaluation. Chem Biol Drug Des. 2014;83:154166. 
15. Reddy Konda K, Singh Kumar $S$, Dessalew N, Tripathi Kumar S, Selvaraj C. Pharmacophore modelling and atom-based 3D-QSAR studies on $\mathrm{N}$-methyl pyrimidones as HIV-1 integrase inhibitors. J Enzyme Inhib Med Chem. 2012; 27:339-47.

16. Telvekar VN, Patel KN. Pharmacophore development and docking studies of the HIV-1 integrase inhibitors derived from $\mathrm{N}$ methylpyrimidones,

dihydroxypyrimidines, and bicyclic pyrimidinones. Chem Biol Drug Des. 2011;78:150-60.

17. Gupta P, Sharma A, Garg P, Roy N QSAR study of curcumine derivatives as HIV-1 integrase inhibitors. Curr Comput Aided Drug Des.2013;9(1):141-50.

18. Frisch MJ, Trucks GW, Schlegel $H B$, Scuderia GE, Robb MA, Cheeseman JR, Scalmani G, Barone V, Mennucci B, Petersson GA, et al. Gaussian 09, Revision a. 02. Gaussian Inc, Wallingford, CT, USA (2009).

19. Case Davi A, . Cheatham III Thomas E, Darden T, Gohlke H, Luo R, Merz
Jr Kenneth M, Onufriev A, Simmerling C, Wang B and Woods R. The Amber biomolecular simulation programs. $J$ Computat Chem. 2005;26, 16681688.

20. Trott O, Olson Arthur J. AutoDock Vina: improving the speed and accuracy of docking with a new scoring function, efficient optimization, and multithreading. J Com Chem. 2010;31: 455-61.

21. Daina A, Michielin O, Zoete V. A free web tool to evaluate pharmacokinetics, drug-likeness and medicinal chemistry friendliness of small molecules. Sci Rep. 2017.3;7:42717.

22. Hare S, Vos Ann M, Clayton Reginald F, Thuring Jan W, Cummings Maxwell $D$, Cherepanov $P$. Molecular mechanisms of retroviral integrase inhibition and the evolution of viral resistance.

PNAS. 2010;107(46):20057-62.

23. Diamond TL, Bushman FD. Role of metal ions in catalysis by HIV integrase analyzed using a quantitative PCR disintegration assay. Nucleic Acids Res. 2006;34(21):611625. 